\title{
The WD40 Domain of HIRA Is Essential for RI-nucleosome Assembly in Xenopus Egg Extracts
}

\author{
Ruibin Zhu, Mari Iwabuchi**, and Keita Ohsumi* \\ Group of Developmental Cell Biology, Graduate School of Science, Nagoya University, Furo-cho, Chikusa-ku, \\ Nagoya 464-8602, Japan
}

\begin{abstract}
Histone chaperones are a group of histone-binding proteins that facilitate the assembly of nucleosomes, the fundamental structural units of chromatin in eukaryotes. In nucleosome assembly, deposition of a histone H3-H4 tetramer onto DNA is the first and critical step, which is mediated by the histone chaperones HIRA and CAF-1. HIRA and CAF-1 are reportedly involved in DNA replication independent (RI) and replication coupled nucleosome assembly, respectively. However, the mechanisms by which they mediate histone deposition remain unclear. In this study, we focused on the mechanism by which HIRA induces RI-nucleosome assembly. We looked for HIRA domains that are required for nucleosome assembly and its localization to chromatin. We used cell-free extracts from Xenopus eggs that carry out RI-nucleosome assembly of plasmid DNA. We confirmed that HIRA formed stable complexes with Asf1, another histone H3-H4 chaperone, and the HIRA-Asf1 complex was solely responsible for RI-nucleosome assembly in egg extracts. We further demonstrated that the HIRA N-terminus containing the WD40 domain, which comprises seven WD40 repeats, and the B domain, to which Asf1 binds, were essential for RI-nucleosome assembly; the three WD40 repeats from the Nterminus were especially critical. Using egg extracts that reproduce nuclear formation accompanying the duplication of chromatin, we also demonstrated that the Hir domain was indispensable for the binding of HIRA to chromatin. Thus, the WD40 and B domains are the core elements for inducing RI-nucleosome assembly. Hir domain regulates the binding to chromatin. Based on these findings, similarities and differences between HIRA and CAF-1 are discussed.
\end{abstract}

Key words: histone chaperone, nucleosome, HIRA, Asf1, WD40 repeat

\section{Introduction}

In eukaryotes, genomic DNA binds histone proteins to form nucleosomes, the fundamental structural units of chromatin. Eukaryotic cells employ a family of proteins termed histone chaperones, to facilitate nucleosome assembly, while preventing nonspecific aggregation of histones and DNA because of the strong electrostatic interactions between the two under physiological conditions. Histone chaperones were initially identified as histone-binding, acidic nuclear proteins, such as nucleoplasmin and N1/N2

\footnotetext{
*To whom correspondence should be addressed: Keita Ohsumi, Group of Developmental Cell Biology, Graduate School of Science, Nagoya University, Furo-cho, Chikusa-ku, Nagoya 464-8602, Japan.

Tel: +81-52-789-2504, Fax: +81-52-789-2504

E-mail: kohsumi@bio.nagoya-u.ac.jp

**To whom correspondence should be addressed: Mari Iwabuchi, Group of Developmental Cell Biology, Graduate School of Science, Nagoya University, Furo-cho, Chikusa-ku, Nagoya 464-8602, Japan.

Tel: +81-52-789-2506, Fax: +81-52-789-2506

E-mail: miwabuchi@bio.nagoya-u.ac.jp
}

of Xenopus laevis eggs, that are able to induce nucleosome assembly of plasmid DNA in vitro (Dilworth et al., 1987; Kleinschmidt et al., 1986; Laskey et al., 1978). Subsequent studies showed that these chaperones do not effectively mediate the deposition of histone $\mathrm{H} 3-\mathrm{H} 4$ tetramers onto double-stranded DNA to give the tetrasome intermediate, the construction of which is the first and most critical step of nucleosome assembly (Elsässer and D'Arcy, 2012; Jorcano and Ruiz-Carrillo, 1979). Nucleoplasmin and $\mathrm{N} 1 / \mathrm{N} 2$ are currently regarded as carriers for a large stockpile of histones stored in eggs (Philpott et al., 2000). More recent studies revealed that, in most eukaryotes, the assembly of tetrasome intermediates that lead to nucleosome assembly is mediated by the two histone H3-H4 chaperones, HIRA (histone regulatory homolog A) and CAF-1 (chromatin assembly factor-1) (Kaufman et al., 1995; RayGallet et al., 2002; Tagami et al., 2004). HIRA is a single polypeptide in metazoans (Kirov et al., 1998). Its counterpart in Saccharomyces cerevisiae consists of two subunits, Hir1 and Hir2 (histone regulatory) (Lamour et al., 1995). 
CAF-1 is a heterotrimeric protein complex (Verreault et al., 1996). Multiple crystallographic analyses suggested that both HIRA and CAF-1 might be indirectly associated with histones $\mathrm{H} 3$ and $\mathrm{H} 4$ through Asf1 (anti-silencing function 1 ), another histone chaperone to which a histone $\mathrm{H} 3-\mathrm{H} 4$ dimer directly binds (English et al., 2006; Natsume et al., 2007; Tang et al., 2006).

Functional distinction between HIRA and CAF-1 has been well documented by the use of cell-free Xenopus egg extracts, which contain all the histone chaperones, HIRA, CAF-1, and Asf1 and reproduce nucleosome assembly of both plasmid DNA without replication and newly synthesized DNA during replication and repair; the former and the latter are referred to as replication-independent (RI) and replication-coupled (RC) nucleosome assembly, respectively (Ray-Gallet and Almouzni, 2004; Ray-Gallet et al., 2007). Studies with Xenopus egg extracts showed that HIRA induces RI-nucleosome assembly (Ray-Gallet et al., 2002, 2007), while CAF-1 specifically facilitates RCnucleosome assembly. Extensive studies with various organisms also indicated that HIRA does not exhibit particular preference for the exact location on chromatin, probably reflective of its involvement in a variety of chromatin regulatory activities including gene transcription, heterochromatin formation, DNA damage repair, and sperm chromatin remodeling (Adam et al., 2013; Anderson et al., 2010; Blackwell et al., 2004; van der Heijden et al., 2005; Loppin et al., 2005; Nashun et al., 2015; Ray-Gallet et al., 2011; Sharp et al., 2002; Zhang et al., 2005). In contrast, CAF-1 localizes to replication forks via binding to PCNA (proliferating cell nuclear antigen) (Moggs et al., 2000; Shibahara and Stillman, 1999). Despite the remarkable difference between HIRA and CAF-1, nucleosomes formed by the two histone $\mathrm{H} 3-\mathrm{H} 4$ chaperones are indistinguishable from each other (Tachiwana et al., 2011). Little is known, however, about the molecular mechanism by which HIRA and CAF-1 induce tetrasome assembly. It is therefore interesting to investigate similarities and differences between the mechanisms by which HIRA and CAF-1 mediate the formation of RI- and RC-nucleosome assemblies, respectively.

To investigate the mechanism by which histone $\mathrm{H} 3-\mathrm{H} 4$ chaperones induce tetrasome assembly, we focused on HIRA, because nucleosome assembly mediated by this chaperone can be analyzed independently of DNA replication, and hence was expected to be simpler than that mediated by CAF-1. In addition, HIRA is a single polypeptide, in which three highly conserved domains have been identified: the WD40 and B domains in the N-terminus, and the Hir domain in the C-terminus (Amin et al., 2012). Of the three domains, the functional role of the $\mathrm{B}$ domain has been well understood, whereas that of the other two remains less clear. Crystallographic analysis demonstrated that B domain is necessary and sufficient for interaction with Asf1, which recruits histones $\mathrm{H} 3$ and $\mathrm{H} 4$ to the chaperone complex (Tang et al., 2006). The WD40 domain has been shown to interact with two histone-binding proteins, UBN1 (ubinuclein 1) and p48 (Ahmad et al., 2003; Banumathy et al., 2009); the former confers specificity of binding to histone H3.3 variant to the HIRA-Asf1 complex (Daniel Ricketts et al., 2015), and the latter, which is also a subunit of CAF-1, binds to a histone H3-H4 dimer (Murzina et al., 2008; Song et al., 2008; Verreault et al., 1996). The Hir domain is shown to be required for binding CABIN1 (calcineurin-binding protein 1), the mammalian ortholog of Hir3 and one of the Hir complex subunits in S. cerevisiae (Rai et al., 2011). It is currently unknown, however, which domains or parts of HIRA are responsible for the deposition of histones $\mathrm{H} 3$ and $\mathrm{H} 4$ onto DNA.

In the present study, we explored HIRA domains which are required for nucleosome assembly and intracellular localization, particularly to chromatin, using high- and low-speed extracts from Xenopus eggs that carry out RInucleosome assembly and nuclear formation accompanying chromatin duplication, respectively (Murray, 1991; RayGallet et al., 2002). We demonstrated that HIRA is constitutively complexed with Asf1, and the HIRA-Asf1 complex is solely responsible for RI-nucleosome assembly in egg extracts. We further showed that the N-terminus of HIRA extending from the WD40 domain to the B domain is required and sufficient for RI-nucleosome assembly. We also demonstrated that the Hir domain is essential for HIRA binding to chromatin. Our results provide a framework for further investigation of detailed mechanisms by which histone $\mathrm{H} 3-\mathrm{H} 4$ chaperones induce tetrasome assembly.

\section{Materials and Methods}

\section{Egg extracts and nuclear fractions}

Low-speed extract (LSE) from unfertilized Xenopus eggs, which were arrested in M phase (M-LSE), was prepared as described by Yamamoto et al. (Yamamoto et al., 2005). Interphase LSE (I-LSE) was prepared by activating M-LSE with $0.4 \mathrm{mM} \mathrm{CaCl}_{2}$, followed by incubation at $22^{\circ} \mathrm{C}$ for $30 \mathrm{~min}$. M- and I-LSE were further centrifuged at $150,000 \mathrm{~g}$ at $4^{\circ} \mathrm{C}$ for $90 \mathrm{~min}$ to obtain high-speed extracts (M- and I-HSE). Permeabilized sperm were prepared as described previously (Ohsumi et al., 2006). To prepare nuclear fractions, permeabilized sperm were added to M-LSE $(1,000 / \mu \mathrm{L})$ along with $0.4 \mathrm{mM} \mathrm{CaCl}_{2}$ and incubated for $90 \mathrm{~min}$ at $22^{\circ} \mathrm{C}$. LSE was then diluted 10-fold with elution buffer (EB) $(100 \mathrm{mM} \mathrm{KCl}, 5$ $\mathrm{mM} \mathrm{MgCl} 2,20 \mathrm{mM}$ HEPES-KOH, $\mathrm{pH} 7.5$ ), layered over a $30 \%$ sucrose/EB cushion and centrifuged at 7,000 $\mathrm{g}$ to precipitate nuclei. Precipitates containing nuclei were washed with $0.25 \%$ Triton X-100/EB to obtain insoluble nuclear fractions including chromatin and nuclear matrices (chromatin fractions). Chromatin proteins were released from the insoluble fractions by micrococcal nuclease digestion (MNase: $1000 \mathrm{U} / \mathrm{ml}, 0.25 \%$ Triton X-100, 12.5 $\mathrm{mM} \mathrm{CaCl}_{2} / \mathrm{EB}$ ) at $22^{\circ} \mathrm{C}$ for $30 \mathrm{~min}$. For control experiments, MLSE without permeabilized sperm was processed as above. 


\section{Immunoprecipitation, immunodepletion, and immunoblotting}

Rabbit antibodies against $X$. laevis HIRA (Xenbase: XB-GENE976075), Asf1 (GenBank accession: BC056123), CAF-1p150 (GenBank accession: AAK31811) and p60 (GenBank accession: DQ192574) were raised against recombinant proteins produced in E. coli. Antigens were as follows: His-HIRAC613 (401-1013), His-Asf1 (1-198), GST-p150C357 (540-896), and GST-p60C325 (245-569). Antibodies against histone H3 (9715, Cell Signaling; ab1791, Abcam), PCNA (PC10, BioLegend), His ${ }_{6}$ (Wako), GST (Wako) and FLAG (M2, Sigma-Aldrich) were purchased. Anti- $X$. laevis lamin LIII antibody was described previously (Hasebe et al., 2011). Immunoprecipitation and immunodepletion were essentially according to Shintomi et al. (2005). Briefly, antibodies were conjugated to Protein G-Sepharose beads (GE Healthcare) by incubating the beads with twice the volume of each antiserum at $20-22^{\circ} \mathrm{C}$ for $1 \mathrm{~h}$. For control experiments, Protein $\mathrm{G}$ beads conjugated with rabbit IgG (Sigma-Aldrich) were used. HSE was incubated with an equal volume of antibody beads at $4^{\circ} \mathrm{C}$ for $1 \mathrm{~h}$ with gentle agitation. Beads were separated from HSE by centrifugation and washed with EB containing $0.25 \%$ Triton X-100. Bead-bound proteins were eluted with SDS sample buffer and analyzed by immunoblotting as described previously (Shintomi et al., 2005).

\section{$c D N A s$}

cDNA fragments encoding HIRA, Asf1, CAF-1p150, p60 and CABIN1 (Xenbase: XB-GENE-6486843) from X. laevis eggs were synthesized by RT-PCR. Deletion mutants of HIRA (FL; 11013) were as follows; $\mathrm{Nt}(1-479), \mathrm{Ct}(421-1013), \Delta \mathrm{B}(\Delta 421-$ 479), $\Delta \mathrm{Ct} 1(\Delta 494-685), \Delta \mathrm{Ct} 2(\Delta 686-850), \Delta \mathrm{Ct} 3(\Delta 851-1013)$, $\Delta$ Hir $(\Delta 737-959)$. For WD40 domain mutants, one, two, and three of WD40 repeat units were deleted. Locations of WD40 repeat units of $X$. laevis HIRA were as follows; WD1: 11-44, WD2: 4598, WD3: 99-159, WD4: 160-202, WD5: 203-255, WD6: 256313, WD7: 314-357.

\section{Preparation of HIRA-Asf1 complexes}

Full-length and deletion mutants of HIRA cDNA were cloned into the pGEX6P-1 plasmid (GE Healthcare) to produce GST-HIRA. Full-length Asf1 cDNA was cloned into the pCDFDuet1 plasmid (Novagen) to produce His-Asf1. For the production of HIRAAsf1 complexes, E. coli strain, Rosetta ${ }^{\mathrm{TM}} 2$ (DE3) was cotransformed with pGEX6P-1-HIRA and pCDFDuet1-Asf1 plasmid. Cells were grown in $2 \times$ YTG medium supplemented with antibiotics $(50 \mu \mathrm{g} / \mathrm{ml}$ ampicillin, $50 \mu \mathrm{g} / \mathrm{ml}$ streptomycin and $34 \mu \mathrm{g} / \mathrm{ml}$ chloramphenicol) at $37^{\circ} \mathrm{C}$ until $\mathrm{OD}_{600}$ reached 0.6 . GSTHIRA and His-Asf1 expression were induced by the addition of $0.2 \mathrm{mM}$ isopropyl $\beta$-D-1 thiogalactopyranoside (IPTG). Cells were shaken at $18^{\circ} \mathrm{C}$ for $19 \mathrm{~h}$, harvested by centrifugation, and lysed by sonication. The GST-HIRA-His-Asfl complex was affinity-purified with Glutathione-Sepharose 4B (GE Healthcare), eluted thrice from the beads with twice the bead bed volume of elution buffer $(10 \mathrm{mM}$ reduced glutathione, $50 \mathrm{mM}$ Tris- $\mathrm{HCl}, \mathrm{pH}$ 8.0) for each elution episode, at $20-22^{\circ} \mathrm{C}$ and concentrated using a centrifugal concentrator (Vivaspin 2, Sartorius). The GST-HIRA protein was mostly insoluble when expressed in E. coli without the co-expression of His-Asf1. Although the soluble GST-HIRA protein was prepared according to the method of Ray-Gallet et al. (2002), using the reticulocyte lysate, instead of E. coli, to produce the recombinant protein, its concentration was not sufficiently high for the use in our assays.

\section{mRNA synthesis}

A cDNA fragment encoding the importin $\beta$-binding domain (IBB) of importin $\alpha$ (Kose et al., 1997) was amplified by PCR and fused to the amino-terminus of the $\mathrm{FLAG}_{3}$ sequence of the pFLAG-C3 plasmid, which is derived from the pBS-RNT3 plasmid carrying the UTRs of $X$. laevis globin mRNA (Lemaire et al., 1995; Sawada et al., 2005) to generate pFLAG-C3-IBB. Full-length and mutant HIRA cDNA were fused to the amino-terminus of the $\mathrm{FLAG}_{3}$ sequence of pFLAG-C3 or the IBB sequence of pFLAG-C3-IBB to produce HIRA-FLAG or HIRA-IBB-FLAG mRNA, respectively. mRNAs were synthesized in vitro using the mMESSAGE mMACHINE T3 kit (Ambion).

\section{Plasmid DNA supercoiling assay}

Supercoiled plasmid DNA (pBluescript II SK, $6.7 \mathrm{ng} / \mu \mathrm{l}$ ) was incubated with I-HSE at $22^{\circ} \mathrm{C}$. The reaction was stopped by adding 4-fold volume of the termination solution (100 mM EDTA, 2\% SDS, $1 \mathrm{mg} / \mathrm{ml}$ Proteinase K, $100 \mathrm{ng} / \mathrm{ml}$ RNase A, $80 \mathrm{mM}$ Tris- $\mathrm{HCl}, \mathrm{pH} 8.0$ ) and incubated at $37^{\circ} \mathrm{C}$ for $1 \mathrm{~h}$. After incubation, plasmid DNA was purified by phenol-chloroform (phenol: chloroform: isoamyl alcohol $=25: 24: 1$ ) extraction, precipitated with ethanol, and separated on 1.5\% agarose gels in TAE buffer. For restoration experiments, each HIRA-Asfl complex was preincubated with HIRA-depleted HSE for 30 min before adding plasmid DNA.

\section{Pull-down experiments}

cDNA fragments encoding the B domain of HIRA (357-457), the B-like domain of p60 (380-569) and the amino-terminal region of CABIN1 (1-937) were ligated into the pGEX6P-1 plasmid to generate GST-HIRA_B, GST-p60_B and CABIN1Nt (1-937), respectively. Recombinant proteins were expressed in E. coli strain, Rosetta $^{\mathrm{TM}} 2$ (DE3) and conjugated to Glutathione-Sepharose 4B. For pull-down experiments, GST-HIRA_B, GST-p60_B and GST conjugated beads were incubated with $\overline{\mathrm{M}}$ - and I-HSE at $20-22^{\circ} \mathrm{C}$ for $2 \mathrm{~h}$. GST and GST-CABIN1Nt conjugated beads were incubated with I-LSE and I-HSE at $20-22^{\circ} \mathrm{C}$ for $2 \mathrm{~h}$. Beads were washed with EB containing $0.25 \%$ Triton $\mathrm{X}-100$. Bead-bound proteins were eluted with SDS sample buffer and analyzed by immunoblotting or Coomassie Brilliant Blue (CBB) staining. 


\section{Results}

\section{Histone H3-H4 chaperone complexes in Xenopus egg extracts}

We first examined Asf1, HIRA, and CAF-1 and their association in high-speed Xenopus egg extracts at interphase (I-HSE), using specific antibodies raised against Xenopus Asf1, HIRA, and the p150 subunit of CAF-1. The results are in agreement with those of a previous study (Ray-Gallet et al., 2007) in which, Asf1 immunodepletion from I-HSE resulted in concomitant depletion of HIRA, whereas immunodepletion of HIRA did not discernibly decrease the Asf1 amount, and CAF-1 was immunodepleted from I-HSE without affecting the amounts of Asf1 and HIRA (Fig. 1A, see Fig. 4A in Ray-Gallet et al., 2007). We also examined the immunoprecipitates from HSE by immunoblotting. When Asfl was immunoprecipitated from extracts at M phase (M-HSE) and I-HSE, HIRA coprecipitated mostly with histone H3, irrespective of the cell-cycle phase (Fig. $1 \mathrm{~B}$, lanes 5-8). On the other hand, CAF-1 coprecipitated partially with Asfl from I-HSE but not from M-HSE (Fig. $1 \mathrm{~B}$, lanes 5-6, 9-10). To examine whether this difference was due to the Asfl binding domains of HIRA and CAF-1, we performed pull-down assays from HSE using the B domain of HIRA and the B-like domain of the p60 subunit of CAF-1. The results demonstrated that Asfl bound to the B domain of HIRA independently of the cell cycle, but bound to the B-like domain of p60 to a lesser extent, only in I-HSE (Fig. 1C, D). These results indicate that in Xenopus eggs, HIRA forms a stable complex with Asf1 throughout the cell cycle, while CAF-1 is partly associated with Asf1 at interphase in a cell-cycle dependent manner. The results also suggest that the difference in Asf1 binding between HIRA and CAF-1 can be attributed to the difference in the properties of their Asfl-binding domain. Our

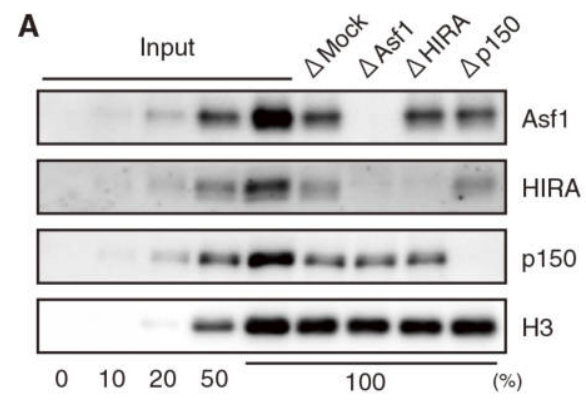

C

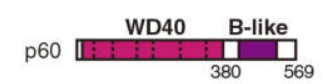

GST-p60_B GST. - प 口

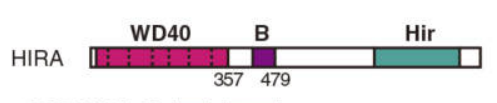

GST-HIRA_B GST.-口

D

B
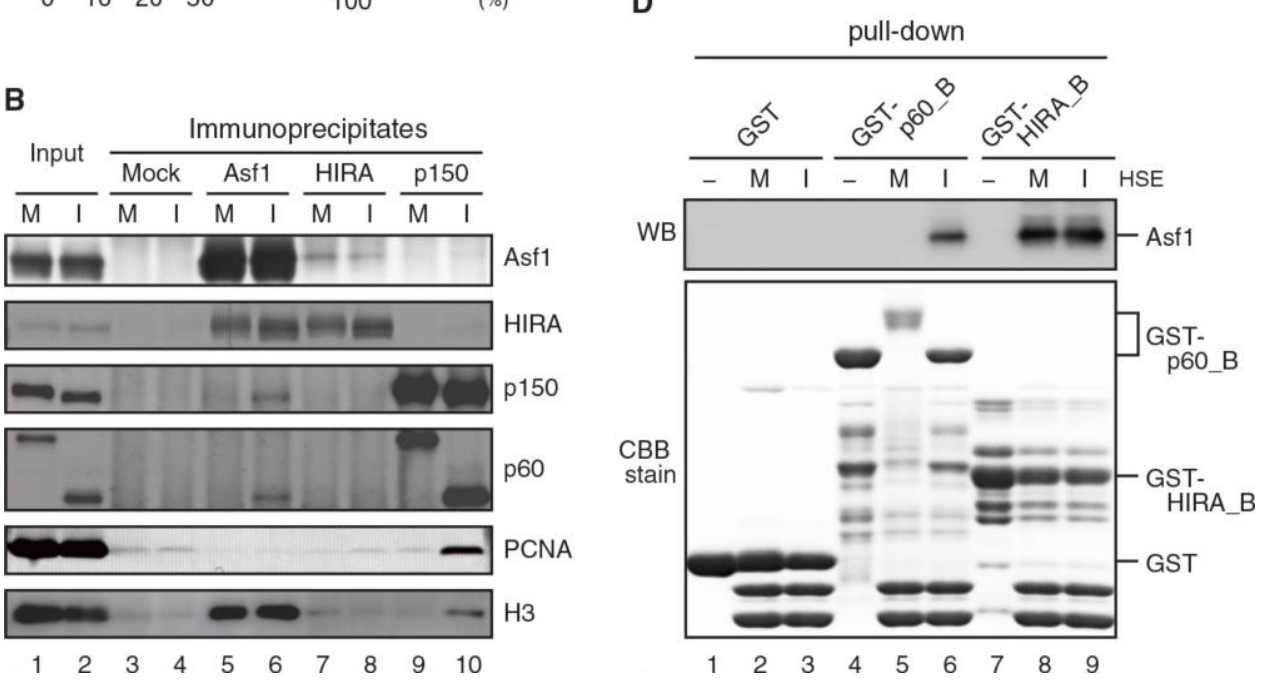

Fig. 1. HIRA forms a stable complex with Asf1 in Xenopus egg extracts. (A) Each of the histone H3-H4 chaperones was selectively immunodepleted from I-HSE by the use of immunobeads coated with either normal rabbit IgG ( $\triangle$ Mock), anti-Asf1, anti-HIRA or anti-p150 (CAF-1) antibodies. Immunodepleted HSEs were analyzed by quantitative immunoblotting. To estimate the efficiency of immunodepletion, increasing volumes $(0,10,20,50$ and $100 \%$ ) of HSE (Input) were run in parallel. (B) Immunobeads coated with either normal rabbit IgG (Mock), anti-Asf1, anti-HIRA or anti-CAF-1p150 antibodies were incubated in M- and I-HSE. The HSEs (Input) and bead-bound proteins (Immunoprecipitates) were immunoblotted with the indicated antibodies. (C) A GST-tagged p60 (CAF-1) fragment (p60_B, 380-569) including the B-like domain and a GST-tagged HIRA fragment (HIRA_B, 357479) including the B domain were used for pull-down assay. (D) Glutathione-sepharose 4B beads coated with GST-p60_B or GST-HIRA_B were used to precipitate endogenous Asf1 from HSE. For control, GST-coated beads were used. The beads were incubated with (M and I) or without (-) M- and I-HSE, and the bead-bound proteins (pull-down) were immunoblotted with anti-Asf1 antibody (top) and analyzed by SDS-PAGE (bottom). 
quantitative immunoblotting further showed that HSE contained Asf1, HIRA and CAF-1 at concentrations of approximately 500, 10, and $5 \mathrm{nM}$, respectively (unpublished results), indicating that in Xenopus eggs, Asf1 is 50- and 100-fold more abundant than HIRA and CAF-1, respectively. Considered together with the stable binding of HIRA to Asf1, this result provides reasons why Asf1 immunodepletion results in HIRA depletion, but not vice versa. Collectively, these results indicate that in Xenopus eggs, the HIRA-Asf1 complex is stably maintained throughout the cell cycle, whereas the CAF-1-Asfl complex is transiently formed at interphase, and Asf1 in complex with histones is mostly free from HIRA and CAF-1 throughout the cell cycle.

\section{The HIRA-Asf1 complex is responsible for RI-nucleosome assembly in egg extracts}

When incubated in I-HSE, supercoiled plasmid DNA (form I) was immediately converted to the relaxed form (form Ir) within $5 \mathrm{~min}$, and then to the supercoiled form again, as a result of RI-nucleosome assembly (Fig. 2A, lanes 1-4 and (Ray-Gallet and Almouzni, 2004)). To confirm the requirement of histone chaperone complexes for RI-nucleosome assembly, we examined the supercoil formation in I-HSE from which Asf1, HIRA, or CAF-1 had been selectively immunodepleted. Consistent with previous results (RayGallet et al., 2007), supercoil formation was severely impaired in I-HSE that had been immunodepleted of Asf1 and HIRA, but not CAF-1 (Fig. 2A, lanes 5-13). This result confirmed that the RI-nucleosome assembly activity in IHSE is dependent on the HIRA-Asf1 complex but not on the CAF-1-Asf1 complex. The result also indicates that Asf1 itself does not induce supercoil formation in the absence of HIRA (Fig. 2A, lanes 8-10). To validate the requirement of the HIRA-Asfl complex for RI-nucleosome assembly, we prepared recombinant HIRA-Asf1 complexes for restoration experiments, using an E. coli co-expression system (Fig. S1A). When the full-length HIRA (FL-HIRA) in complex with Asf1 was added to HIRA-depleted I-HSE, supercoil formation was successfully restored (Fig. 2B, lanes 5-7) in a dose-dependent manner (Fig. 2C, D). This result demonstrates that the RI-nucleosome assembly activity in I-HSE can exclusively be ascribed to the HIRA-Asf1 complex. Recombinant HIRA protein, along with exogenously added histones $\mathrm{H} 3$ and $\mathrm{H} 4$, reportedly induces RInucleosome assembly in Asfl-depleted HSE (Ray-Gallet $e t$ al., 2007). However, we could not produce recombinant HIRA protein without the co-expression of Asf1 in E. coli. Owing to this technical difficulty, we could not investigate whether HIRA induced the supercoil formation by itself in the absence of Asfl in I-HSE.

\section{The WD40 domain of HIRA is critical for RI-nucleosome assembly}

To gain some insights into the mechanism by which the HIRA-Asf1 complex induces RI-nucleosome assembly, we investigated which domains, other than the $\mathrm{B}$ domain, of HIRA were required for RI-nucleosome assembly. We, therefore, prepared two truncated mutants of HIRA in complex with Asf1; an N-terminal fragment of HIRA (NtHIRA) extending from the $\mathrm{N}$-terminus to the $\mathrm{B}$ domain and a C-terminal fragment of HIRA (Ct-HIRA) extending from the $\mathrm{B}$ domain to the C-terminus (Fig. 2H; Fig. S1A). Each of the complexes was added to HIRA-depleted I-HSE and supercoil formation in the I-HSE was examined. The result clearly demonstrated that the Nt-HIRA-Asfl complex was as effective as the FL-HIRA-Asfl complex in restoring the nucleosome assembly activity, whereas the Ct-HIRA-Asf1 complex was ineffective (Fig. 2B). This result strongly suggests that the N-terminus of HIRA, which includes the WD40 and B domains, is necessary and sufficient for the HIRA-Asf1 complex to mediate the deposition of histones $\mathrm{H} 3$ and $\mathrm{H} 4$ onto the plasmid DNA for nucleosome assembly.

The WD40 domain of HIRA consists of seven copies of a WD40 repeat (Kirov et al., 1998; Lamour et al., 1995). We further examined whether all the seven WD40 repeats were necessary for nucleosome assembly. We first tested HIRA mutants from which three continuous WD40 repeats were deleted; deletion of WD1, 2, and 3 ( $\Delta 1-3$-HIRA) and WD5, 6, and 7 ( $\triangle 5-7$-HIRA). The results clearly demonstrated that the $\Delta 5-7$-HIRA-Asf1 complex restored supercoil formation to HIRA-depleted I-HSE as did the FLHIRA-Asf1 complex, whereas the $\Delta 1$-3-HIRA-Asf1 complex did not (Fig. 2E). Thus, WD40 repeats from WD1 to 3, but not those from WD5 to 7, of HIRA are indispensable for the nucleosome assembly activity of the HIRA-Asf1 complex, indicating that the seven WD40 repeats are not functionally equivalent to one another for inducing nucleosome assembly. We next tested HIRA mutants from which two of the three indispensable WD40 repeats were deleted; deletion of WD1 and $2(\Delta 1,2-\mathrm{HIRA}), \mathrm{WD} 2$ and $3(\Delta 2,3-$ HIRA), and WD1 and $3(\Delta 1,3-H I R A)$. The result showed that the $\Delta 1,2-$ and $\Delta 2,3-$ HIRA-Asfl complexes restored supercoil formation to HIRA-depleted I-HSE but were less effective than the FL-HIRA-Asf1 complex (Fig. 2F, lanes 5-10). Moreover, the $\Delta 1,3-$ HIRA-Asfl complex was completely ineffective in inducing supercoil formation (Fig. 2F, lanes 11-13). Thus, the nucleosome assembly activity of the HIRA-Asf1 complex is severely impaired by the deletion of WD1 and 3 and is attenuated by the deletion of two WD40 repeats including either WD1 or 3. Lastly, we tested HIRA mutants from which single WD40 repeat of the three indispensable ones was deleted: deletion of WD1 $(\Delta 1-$ HIRA), WD2 ( $\triangle 2$-HIRA), and WD3 ( $\Delta 3$-HIRA). The result showed that all the single WD-deletion mutants in complex with Asfl restored the nucleosome assembly 
A

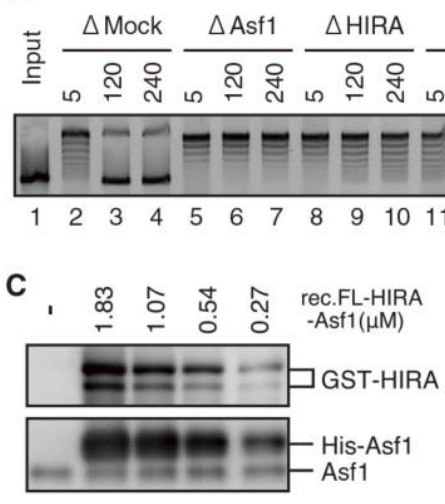

B

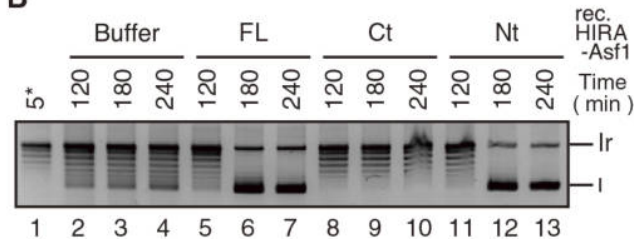

$\mathbf{E}$

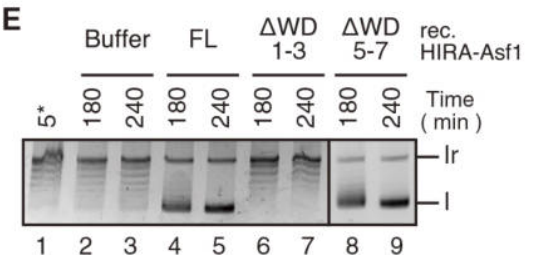

G

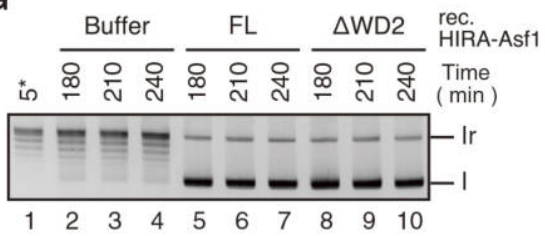

D

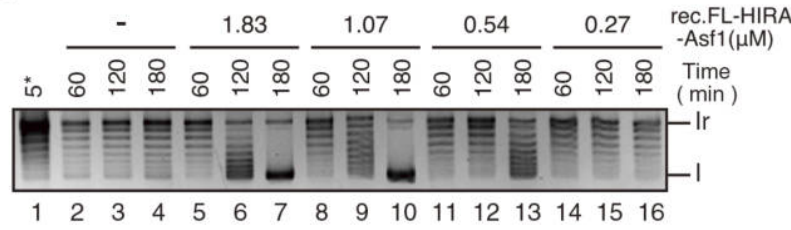

$\mathbf{F}$

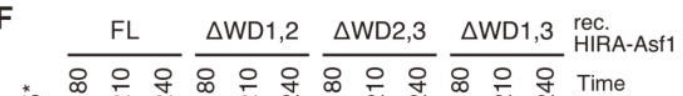

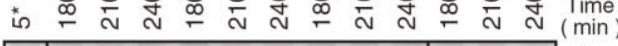

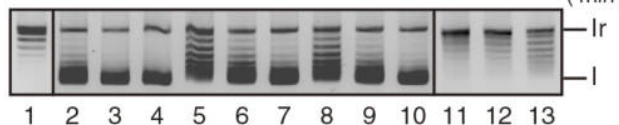

H

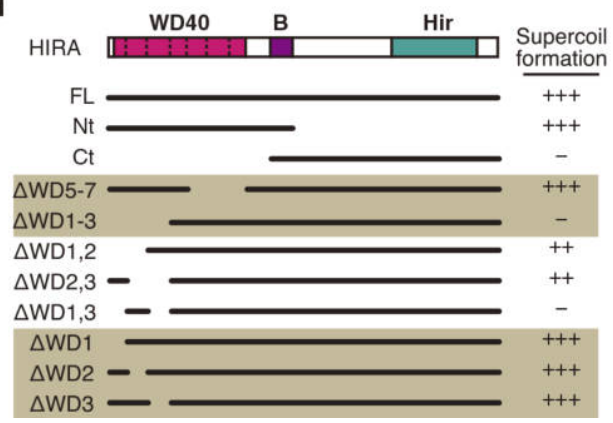

Fig. 2. WD40 domain of HIRA is essential for RI-nucleosome assembly. (A) Plasmid DNA was incubated for the indicated times in I-HSEs from which each histone chaperone had been selectively immunodepleted (as in Fig. 1A), and then separated on agarose gels. The supercoiled DNA (Input) was run in parallel, and the migration positions of relaxed (Ir) and supercoiled DNA (I) are indicated on the right. (B) The HIRA-depleted I-HSE was supplemented with buffer or one of the recombinant HIRA mutants (FL, C- and N-terminus) in complex with Asfl. After incubation in the I-HSEs for the indicated times, plasmid DNA was separated on agarose gels. The plasmid DNA pre-incubated in HIRA-depleted I-HSE for 5 min ( $\left.5^{*}\right)$ was run in parallel. (C-D) The HIRA-depleted I-HSE was supplemented with $1.83,1.07,0.54$ and $0.27 \mu \mathrm{M}$ or without (-) recombinant full-length (FL) HIRA in complex with Asfl. Each of the I-HSEs was immunoblotted with anti-HIRA and anti-Asf1 antibodies (C). After incubation in the I-HSEs for the indicated times, plasmid DNA was separated on agarose gels (D). The plasmid DNA pre-incubated in the HIRA-depleted I-HSE for 5 min (5*) was run in parallel. (E-G) The supercoiling assay using the HIRA-depleted HSE supplemented with either buffer or recombinant HIRA in complex with Asf1 was carried out as in Fig. 2B. (H) Schematic diagram that summarizes the supercoiling activity of $X$. laevis HIRA mutants. The rate of supercoiling was measured and scored at specified intervals after incubation. The scoring system was as follows. $+++:>80 \%$ at $180 \mathrm{~min},++:>80 \%$ at $210 \mathrm{~min},-:<80 \%$ at $240 \mathrm{~min}$. The three HIRA domains that are highly conserved in eukaryotes are colored. WD40, B, and Hir indicate the WD40 domain comprised of seven WD-repeats, the Asfl-binding B domain, and the Hir/HIRA homologous domain, respectively.

activity as effectively as the FL-HIRA-Asfl complex (Fig. $2 \mathrm{G}$; Fig. S1B), indicating that none of the WD40 repeats individually is critical for nucleosome assembly. Taken together, these results indicate that WD1 and 3 of HIRA, which may be functionally redundant, are the most crucial for the nucleosome assembly activity of the HIRA-Asf1 complex.

\section{Hir domain is required for chromatin binding of the HIRA-Asf1 complex}

We also investigated which domain of HIRA is involved in the regulation of its intracellular localization, particularly to chromatin, using low-speed extracts from Xenopus eggs (LSE), which reproduce nucleosome assembly, nuclear formation of sperm DNA, and translation of exogenously 

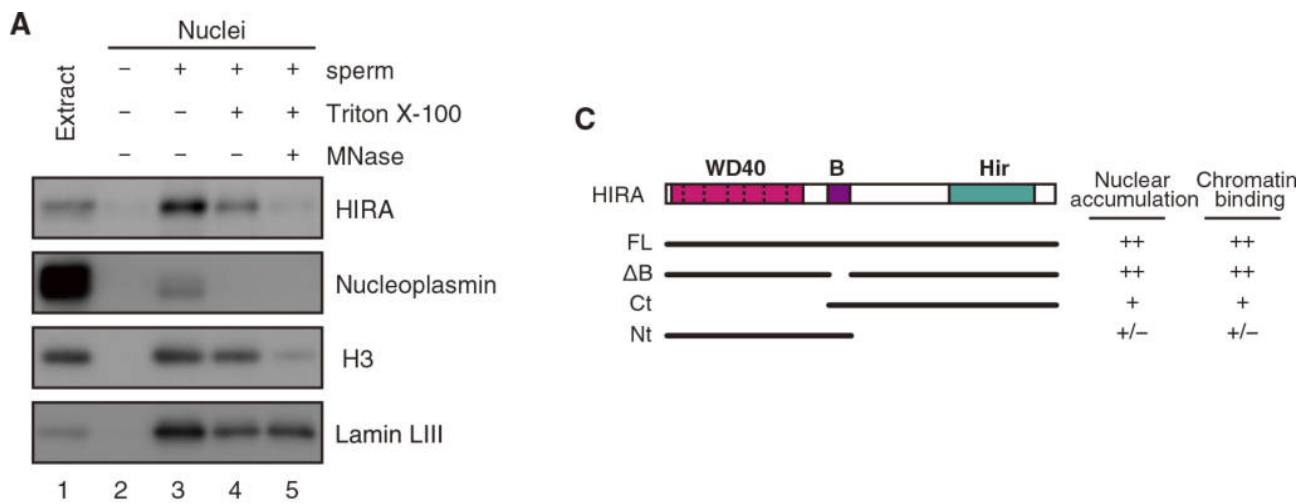

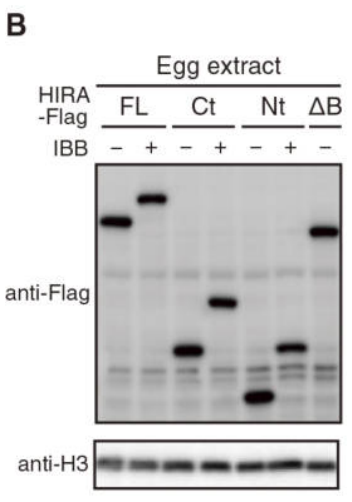

$\begin{array}{lllllll}1 & 2 & 3 & 4 & 5 & 6 & 7\end{array}$

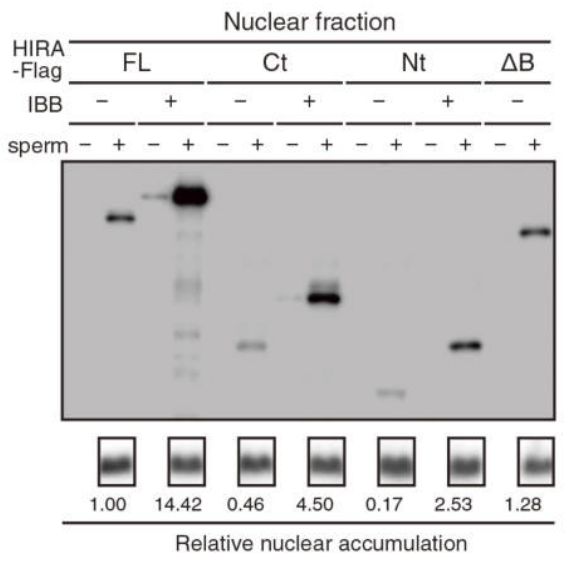

89101112131415161718192021

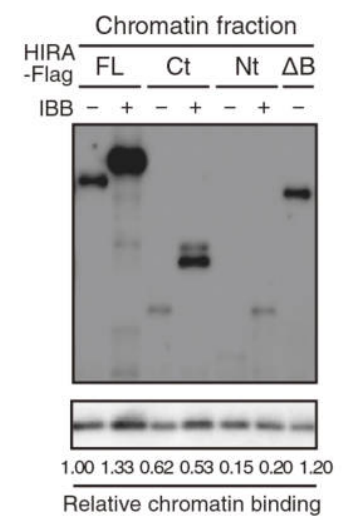

22232425262728

Fig. 3. HIRA accumulates in the nucleus and binds to chromatin in egg extracts. (A) Permeabilized sperm were incubated in I-LSE for 90 min to induce nuclear formation. Nuclei were precipitated by centrifugation (lane 3), and then treated with detergent $(0.25 \%$ Triton X-100, lane 4) to permeabilize the nuclear envelope, followed by digestion with micrococcal nuclease (MNase, $1000 \mathrm{U} / \mathrm{ml}$ ) to remove chromatin-bound proteins (lane 5). Precipitates obtained by centrifugation of egg extracts without sperm addition served as a negative control (lane 2). I-LSE (extract, lane 1) and each fraction were analyzed by immunoblotting. (B) FLAG-tagged HIRA fused with or without the IBB sequence was translated from mRNA in I-LSE (Egg extract, left). Sperm chromatin was incubated in the I-LSEs for nuclear formation, and the nuclei (sperm ${ }^{+}$) were collected by centrifugation (Nuclear fraction, center). Precipitates obtained by centrifugation of I-LSEs without sperm addition (sperm-) served as a negative control. The permeabilized nucleus as a chromatinbinding fraction was obtained by detergent-treatment (Chromatin fraction, right). All fractions were immunoblotted with indicated antibodies. Relative nuclear accumulation (nuclear fraction $\left[\left(\right.\right.$ sperm $\left.^{+}\right)-\left(\right.$sperm- $\left.\left.^{-}\right)\right] /$egg extract) and relative chromatin binding (chromatin fraction/nuclear fraction) are calculated taking the value of FL-HIRA-FLAG without IBB (IBB-) as 1.00 and are shown at the bottom. (C) Schematic diagram that summarizes nuclear accumulation and chromatin binding activities of $X$. laevis HIRA mutants as evaluated by the relative values indicated at the bottom of each panel (++: $>0.8,+:>0.4,+/-:<0.4)$.

introduced mRNA (Lohka and Masui, 1983; Murray, 1991). To prepare nuclear and chromatin fractions, permeabilized sperm were incubated in LSE at interphase (I-LSE) and nuclei were collected by centrifugal precipitation (nuclear fraction, Fig. 3A, lane 3; Fig. 3B, middle panel), followed by detergent-treatment to obtain insoluble fractions including chromatin (chromatin fraction, Fig. 3A, lane 4; Fig 3B, right panel). In some experiments, insoluble fractions were further treated with MNase to confirm whether a certain protein in question actually bound to chromatin or was associated with insoluble nuclear matrices (Fig. 3A, lane 5; Fig. S2). In the fractionation, the endogenous HIRA protein was contained in the chromatin fraction and was not present in the MNase-treated nuclear fraction, like histone $\mathrm{H} 3$, indicating nuclear accumulation and chromatin binding of HIRA (Fig. 3A). To examine which domains of HIRA are involved in its nuclear accumulation and chromatin binding, each of the various FLAG-tagged HIRA-mutant proteins was expressed in ILSE to similar levels (Fig. 3B, left panel), and permeabilized sperm were subsequently added to the I-LSE to induce nuclear formation. When FL-HIRA was expressed in I-LSE, the protein was contained in both nuclear and chromatin fractions as was endogenous HIRA (Fig. 3A; Fig. 3B, lanes 9, 22), and was released from the chromatin fraction along with histone H3 by MNase treatment (Fig. $\mathrm{S} 2$ ). This result demonstrates that FL-HIRA efficiently accumulates in the nucleus and binds to chromatin as does 
A

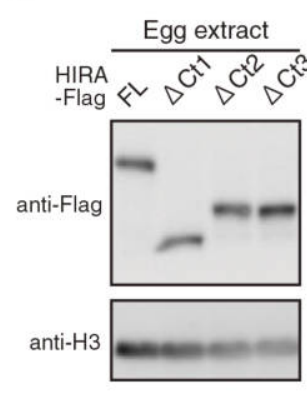

1234

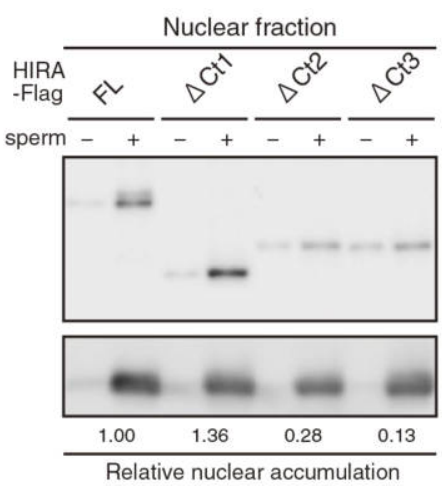

$\begin{array}{llllllll}5 & 6 & 7 & 8 & 9 & 10 & 11 & 12\end{array}$
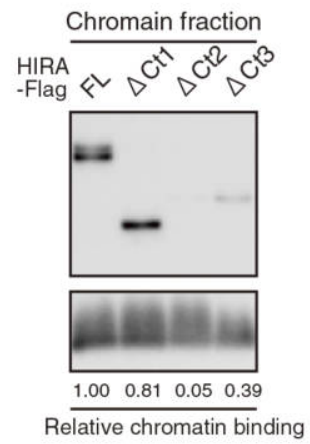

$131415 \quad 16$
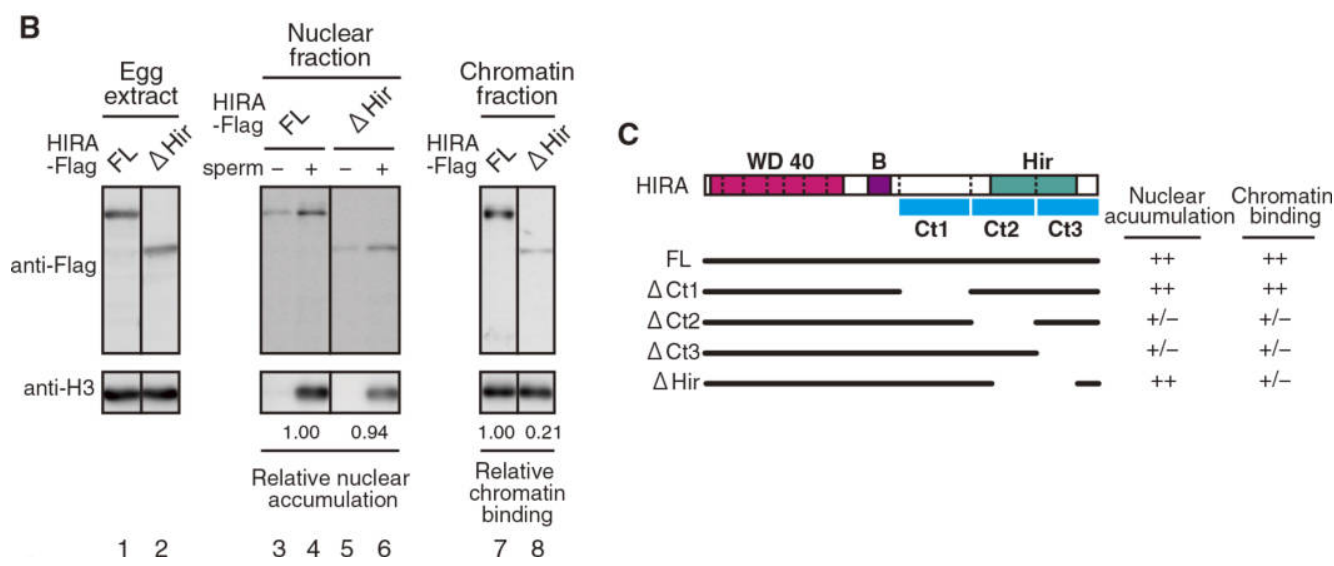

Fig. 4. Hir domain is required for chromatin binding of HIRA. (A and B) Egg extract (I-LSE), nuclear fraction, and chromatin fraction were obtained and analyzed as in Fig. 3B. (C) Schematic diagram that summarizes both nuclear accumulation and chromatin binding activities of $X$. laevis HIRA mutants as evaluated by the relative values indicated at the bottom of each panel $(++:>0.8,+:>0.4,+/-:<0.4)$. The C-terminus of HIRA is arbitrarily divided into three regions, which is indicated by the blue bar (Ct1: 494-685, Ct2: 686-850, and Ct3: 851-1013).

the endogenous HIRA protein. Interestingly, when HIRA from which the $\mathrm{B}$ domain has been deleted ( $\triangle \mathrm{B}$-HIRA) was similarly examined, $\triangle \mathrm{B}$-HIRA accumulated in the nucleus (Fig. 3B, lane 21) and bound to chromatin (Fig. 3B, lane 28) as did FL-HIRA. This result indicates that Asfl binding is not required for the nuclear accumulation and chromatin binding of HIRA (Fig. 3C).

When Nt-HIRA or Ct-HIRA was expressed in I-LSE, the extent of nuclear accumulation of either HIRA fragment was much lower than that of FL-HIRA (Fig. 3B, lanes 13, 17 ), suggesting that both termini are involved in effective nuclear localization of HIRA. Although the result also suggested that Ct-HIRA, but not Nt-HIRA, efficiently bound to chromatin (Fig. 3B, lanes 24, 26), this distinction was not conclusive because the amounts of the chromatin-bound proteins were small owing to the low levels of their nuclear accumulation. To confirm the result, we enhanced the nuclear accumulation of the HIRA mutants by adding the importin $\beta$-binding domain (IBB) sequence to them (Fig. $3 \mathrm{~B}$, compare lanes 13 and 17 to lanes 15 and 19, respec- tively). By enhancing the nuclear accumulation of $\mathrm{Ct}$ - and Nt-HIRA, it was unambiguously demonstrated that CtHIRA was positive (Fig. 3B, lane 25) and Nt-HIRA was negative (Fig. 3B, lane 27) for chromatin binding. Thus, the $\mathrm{C}$-terminus, but not the $\mathrm{N}$-terminus, is required for chromatin binding of HIRA (Fig. 3C).

To identify HIRA domain required for chromatin binding, we tested a series of HIRA deletion mutants (Fig. 4, $\Delta \mathrm{Ct} 1-, \Delta \mathrm{Ct} 2-$, and $\Delta \mathrm{Ct} 3-\mathrm{HIRA})$ and found that it was located in the $\mathrm{Ct} 2$ and $\mathrm{Ct} 3$ region of the $\mathrm{C}$-terminus (Fig. 4A). Since the C-terminal region includes the highly conserved Hir domain, which is also known to interact with CABIN1 (Rai et al., 2011), we tested whether HIRA from which the Hir domain had been deleted ( $\triangle$ Hir-HIRA) bound to chromatin. The result demonstrated that $\triangle$ Hir-HIRA was as ineffective as Nt-HIRA for chromatin binding, although the mutant accumulated in the nucleus as efficiently as FLHIRA (Fig. 4B). A pull-down assay suggested that the Hir domain is required for CABIN1 binding to HIRA in Xenopus eggs (Fig. S3). Thus, the Hir domain is indispensable 
for the chromatin binding of HIRA, which is likely mediated through CABIN1. The results of the present study suggest that multiple domains of HIRA are involved in the regulation of nuclear localization, indicating that the nuclear localization of proteins depends not only on nuclear import but also on nuclear export and nuclear retention by anchoring to nuclear chromatin and/or matrices.

\section{Discussion}

Consistent with the previous studies with Xenopus egg extracts (Ray-Gallet et al., 2002, 2007), the results of the current study demonstrated that HIRA forms a stable complex with Asf1 throughout the cell cycle. The supercoiling of plasmid DNA, i.e., RI-nucleosome assembly in I-HSE is induced exclusively by the HIRA-Asfl complex. The persistence of the HIRA-Asf1 complex might be specific to eggs and early embryonic cells of Xenopus, in which rapid nucleosome assembly of replicating chromatin is required owing to cell divisions occurring at intervals as short as 30 min. It was reported, however, that HIRA and Asf1 are colocalized to nucleosome-free DNA and to PML bodies in Drosophila and mammalian cells, respectively (Jiang et al., 2011; Schneiderman et al., 2012). Physical interaction between HIRA and Asf1 is required for the formation of senescence-associated heterochromatin foci in mammalian cells (Zhang et al., 2007). Similarly, in S. cerevisiae, Asf1 and Hir proteins form a complex, which is essential for nucleosome assembly and gene silencing (Daganzo et al., 2003; Green et al., 2005). It has been shown in the present study that when HIRA and Asf1 fusion proteins were coexpressed in E. coli, they formed a stable complex that exhibited RI-nucleosome assembly activity in HSE. We conclude therefore that HIRA generally forms a complex with Asfl in vivo and functions as a histone chaperone in the form of the complex. HIRA is reportedly able to induce RI-nucleosome assembly in the absence of Asf1 in a Xenopus egg extract similar to that used in the present study (Ray-Gallet et al., 2007). This might be due to the presence of excess histones $\mathrm{H} 3$ and $\mathrm{H} 4$ that have been supplemented in the extract.

We demonstrated that CAF-1, in contrast, is complexed with Asf1 only partially and transiently in a cell-cycle dependent manner in Xenopus eggs. We have found that CAF-1-dependent RC-nucleosome assembly in I-LSE is severely impaired by immunodepletion of Asfl, although histone $\mathrm{H} 3$ mostly remained in the Asfl-depleted I-LSE (cf. Fig. 1A). In addition, Asf1 effectively coprecipitated with CAF-1 along with PCNA when the p150 subunit is immunoprecipitated from MNase-digested replicating chromatin (manuscript in preparation). Thus, our results are in agreement with those of previous studies (Mello et al., 2002; Tyler et al., 1999) and strongly suggest that Asf1 binding is required not only for HIRA but for CAF-1 to function as a histone chaperone and mediate the deposition of histones $\mathrm{H} 3$ and $\mathrm{H} 4$ onto DNA for nucleosome assembly. We showed that the remarkable difference between HIRA and CAF-1 in Asf1 binding is attributable to the difference in their Asfl-binding domains, although these domains share the amino acids critical for Asfl binding (Tang et al., 2006). It is likely, therefore, that the access of Asfl to the B-like domain of CAF-1 is regulated such that CAF-1 mediates nucleosome assembly only when associated with the machinery for DNA replication during interphase. Regarding the cell cycle-dependent regulation of Asf1 binding to CAF-1, it was observed that the electrophoretic mobility of the C-terminus of the p60 subunit of CAF-1, which harbors the B-like domain, is remarkably reduced at $\mathrm{M}$ phase owing to phosphorylation (see Fig. 1C, lane 5). The regulatory mechanism for cell cycle- and DNA replication-dependent Asf1 binding to CAF-1 deserves further detailed analysis.

The present results demonstrated that the N-terminus fragment of HIRA extending from the WD40 domain to the B domain is sufficient for the HIRA chaperone complex to induce RI-nucleosome assembly in I-HSE. Both the WD40 and $\mathrm{B}$ domains are highly conserved in HIRA/Hir proteins from yeast to humans (Amin et al., 2012). We further found that among the seven WD40 repeats of HIRA, the first to third repeats from the $\mathrm{N}$ terminus (WD1 to WD3) are critically important, whereas the fifth to seventh repeats (WD5 to WD7) are not essential for the nucleosome assembly activity. Interestingly, any two WD40 repeats out of the indispensable three are sufficient for the complete nucleosome assembly activity. Among the first three repeats, WD1 and WD3 are more critical than WD2 because the nucleosome assembly activity was completely abolished by the deletion of WD1 and 3, whereas it was diminished by the deletion of WD1 and 2 or WD2 and 3. These results suggest that the three WD40 repeats are functionally redundant in nucleosome assembly. Regarding the mechanism of regulation of histone-DNA binding, it is possible that the WD40 domain of HIRA directly mediates histone deposition onto DNA since WD40 repeats are known to bind both DNA and histone proteins (Fischer et al., 2011; Murzina et al., 2008; Ruthenburg et al., 2006; Song et al., 2008). Alternatively, since WD40 repeats are also known to coordinate the assembly of multiple protein complexes (see review Xu and Min, 2011), the WD40 domain of HIRA may operate as a platform to build protein complexes required for nucleosome assembly. It is intriguing that the WD5 of the Drosophila HIRA is a binding target of UBN1, which confers histone H3.3 binding specificity on the HIRA histone chaperone complex (Banumathy et al., 2009; Daniel Ricketts et al., 2015). As the WD40 repeats are highly conserved in HIRA/Hir proteins across species, the WD5 of Xenopus is possibly targeted by UBN1, suggesting collaborative interactions among WD40 repeats in the selective deposition of a certain histone variant. Whatever 
HIRA
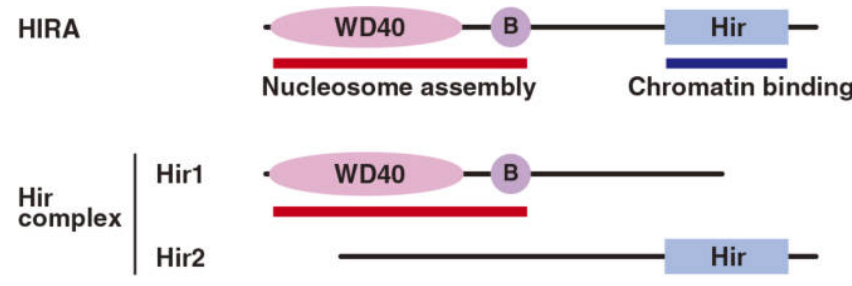

Hir2

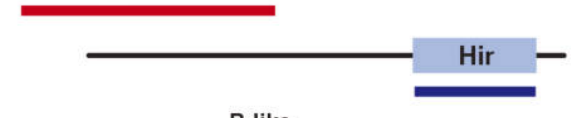

CAF-1

p60
p150

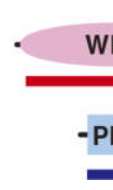

Fig. 5. Similarities and differences in the functional domains of HIRA and CAF-1. HIRA of metazoan species harbors the three highly conserved domains, the WD40, B, and Hir domains. Of the three, WD40 and B domains, along with Asfl, constitute the functional unit of histone chaperone and play an essential role in the deposition histones $\mathrm{H} 3$ and $\mathrm{H} 4$ onto DNA, to induce nucleosome assembly. The Hir domain is required for the binding of HIRA to chromatin, constituting the other functional unit of the histone chaperone to regulate the chromatin binding of the histone chaperone. The two functional units are separately located on different subunits of the Hir complex in S. cerevisiae. The nucleosome assembly and the chromatin-binding units are on Hir1 and Hir2, respectively. Similarly, in the CAF-1 complex, the WD40 and B-like domains, corresponding to the nucleosome assembly unit, and the PIP box, corresponding to the chromatin-binding unit, are on the p60 and p150 subunits, respectively.

might be the mechanism, the WD40 domain of HIRA was found to play an essential role in mediating deposition of histones $\mathrm{H} 3$ and $\mathrm{H} 4$ onto DNA for nucleosome assembly.

Using I-LSE, which carries out nuclear formation and chromatin replication in vitro, we demonstrated that the Hir domain is required for chromatin binding of HIRA. As the Hir domain, to which CABIN1/Hir3 binds (Rai et al., 2011), is also well conserved among HIRA/Hir proteins, HIRA binding to chromatin is likely mediated by CABIN1. Our results supported the requirement of Hir domain for CABIN1 binding to HIRA in Xenopus egg extracts. It is therefore very likely that the Hir domain is responsible for chromatin binding of HIRA. As for HIRA domain involvement in its nuclear localization, it turned out that both the $\mathrm{N}$ - and C-termini are required for nuclear accumulation of HIRA. However, the exact domains were not identified, probably because nuclear localization can be affected by multiple factors including nuclear import, nuclear export, and nuclear retention by binding to chromatin and/or nuclear matrices. Although it was reported that $S$. cerevisiae Hir1 and Hir2 possess nuclear localization signal (NLS) sequences, which appear to contribute to nuclear import of the Hir complex (Sherwood et al., 1993), we did not find any functional NLS in Xenopus HIRA. Although the precise mechanism for nuclear localization of Xenopus HIRA remains unclear, our results demonstrated that HIRA by itself is able to localize to the nucleus and bind to chro-

matin independently of Asf1.

The WD40, B, and Hir domains are highly conserved in HIRA/Hir proteins (Amin et al., 2012; Lamour et al., 1995). It has been established that the B domain is required for Asf1 binding, through which histones $\mathrm{H} 3$ and $\mathrm{H} 4$ are provided to histone chaperone complexes (Tang et al., 2006). In addition, the present study demonstrated that the WD40 and Hir domains are essential for RI-nucleosome assembly by the HIRA-Asf1 complex and chromatin binding of the complex, respectively (Fig. 5). We further demonstrated that the N-terminus of HIRA extending from the WD40 domain to the B domain (the WD40-B domain) is sufficient for the HIRA-Asf1 complex to induce RInucleosome assembly in HSE. The WD40 domain at the Nterminus of HIRA and the B domain at its C-terminal side with an intervening region of approximately 60 amino acids are highly conserved in HIRA/Hir proteins across species. Therefore, it is suggested that the WD40 domain together with the B domain constitute a functional unit of HIRA that recruits and deposits histones $\mathrm{H} 3$ and $\mathrm{H} 4$ onto DNA for RInucleosome assembly. The Hir domain, which is responsible for chromatin binding, and the WD40-B domain are not necessarily located on the same polypeptide. For example, in S. cerevisiae, the WD40-B and Hir domains are separately located in the Hir1 and Hir2 proteins, respectively. Thus, the Hir domain can be inherited separately from the WD40-B domain, suggesting that the Hir domain constitutes another functional unit of HIRA. We speculate therefore that HIRA is composed of at least two functional modules for nucleosome assembly and chromatin binding (see Fig. 5).

CAF-1 is similarly composed of the two functional modules, the p60 and p150 subunits containing nucleosome assembly and chromatin binding modules, respectively. Thus, the feature of two functional modules is common to both HIRA and CAF-1. To obtain a unifying framework for understanding the fundamental structure and function of histone H3-H4 chaperone complexes, irrespective of RI- or $\mathrm{RC}$ mode of nucleosome assembly, it is worth exploring similarities and differences between the HIRA-Asfl and CAF-1-Asf1 complexes and their spatio-temporal regulation in nucleosome assembly. The depletion/add-back assay with Xenopus egg extracts will provide a powerful tool to study further the mechanisms by which the histone chaperone complex mediates nucleosome assembly.

Acknowledgments. We thank K. Shintomi for his help in preparing some antibodies. This work was supported by JSPS KAKENHI Grant Numbers, JP26650005 (M.I.) and JP26650058 (K.O.).

\section{References}

Adam, S., Polo, S.E., and Almouzni, G. 2013. Transcription recovery after DNA damage requires chromatin priming by the $\mathrm{H} 3.3$ histone chaperone HIRA. Cell, 155: 94-106.

Ahmad, A., Takami, Y., and Nakayama, T. 2003. WD dipeptide motifs and LXXLL motif of chicken HIRA are necessary for transcription 
repression and the latter motif is essential for interaction with histone deacetylase-2 in vivo. Biochem. Biophys. Res. Commun., 312: 12661272.

Amin, A.D., Vishnoi, N., and Prochasson, P. 2012. A global requirement for the HIR complex in the assembly of chromatin. Biochim. Biophys. Acta-Gene Regul. Mech., 1819: 264-276.

Anderson, H.E., Kagansky, A., Wardle, J., Rappsilber, J., Allshire, R.C., and Whitehall, S.K. 2010. Silencing mediated by the Schizosaccharomyces pombe HIRA complex is dependent upon the Hpc2-like protein, Hip4. PLoS One, 5: e13488.

Banumathy, G., Somaiah, N., Zhang, R., Tang, Y., Hoffmann, J., Andrake, M., Ceulemans, H., Schultz, D., Marmorstein, R., and Adams, P.D. 2009. Human UBN1 is an ortholog of yeast Hpc2p and has an essential role in the HIRA/ASF1a chromatin-remodeling pathway in senescent cells. Mol. Cell. Biol., 29: 758-770.

Blackwell, C., Martin, K.A., Greenall, A., Pidoux, A., Allshire, R.C., and Whitehall, S.K. 2004. The Schizosaccharomyces pombe HIRA-like protein Hip1 is required for the periodic expression of histone genes and contributes to the function of complex centromeres. Mol. Cell. Biol., 24: 4309-4320.

Daganzo, S.M., Erzberger, J.P., Lam, W.M., Skordalakes, E., Zhang, R., Franco, A.A., Brill, S.J., Adams, P.D., Berger, J.M., and Kaufman, P.D. 2003. Structure and function of the conserved core of histone deposition protein Asf1. Curr. Biol., 13: 2148-2158.

Daniel Ricketts, M., Frederick, B., Hoff, H., Tang, Y., Schultz, D.C., Singh Rai, T., Grazia Vizioli, M., Adams, P.D., and Marmorstein, R. 2015. Ubinuclein-1 confers histone H3.3-specific-binding by the HIRA histone chaperone complex. Nat. Commun., 6: 7711.

Dilworth, S.M., Black, S.J., and Laskey, R.A. 1987. Two complexes that contain histones are required for nucleosome assembly in vitro: role of nucleoplasmin and N1 in Xenopus egg extracts. Cell, 51: 1009-1018.

Elsässer, S.J. and D'Arcy, S. 2012. Towards a mechanism for histone chaperones. Biochim. Biophys. Acta, 1819: 211-221.

English, C.M., Adkins, M.W., Carson, J.J., Churchill, M.E.A., and Tyler, J.K. 2006. Structural basis for the histone chaperone activity of Asf1. Cell, 127: 495-508.

Fischer, E.S., Scrima, A., Böhm, K., Matsumoto, S., Lingaraju, G.M., Faty, M., Yasuda, T., Cavadini, S., Wakasugi, M., Hanaoka, F., Iwai, S., Gut, H., Sugasawa, K., and Thomä, H. 2011. The Molecular Basis of CRL4DDB2/CSA Ubiquitin Ligase Architecture, Targeting, and Activation. Cell, 147: 1024-1039.

Green, E.M., Antczak, A.J., Bailey, A.O., Franco, A.A., Wu, K.J., Yates, J.R., and Kaufman, P.D. 2005. Replication-independent histone deposition by the HIR complex and Asf1. Curr. Biol., 15: 2044-2049.

Hasebe, T., Kajita, M., Iwabuchi, M., Ohsumi, K., and Ishizuya-Oka, A. 2011. Thyroid hormone-regulated expression of nuclear lamins correlates with dedifferentiation of intestinal epithelial cells during Xenopus laevis metamorphosis. Dev. Genes Evol., 221: 199-208.

van der Heijden, G.W., Dieker, J.W., Derijck, A.A.H.A., Muller, S., Berden, J.H.M., Braat, D.D.M., van der Vlag, J., and de Boer, P. 2005. Asymmetry in Histone H3 variants and lysine methylation between paternal and maternal chromatin of the early mouse zygote. Mech. Dev., 122: $1008-1022$.

Jiang, W.Q., Nguyen, A., Cao, Y., Chang, A.C.M., and Reddel, R.R. 2011. HP1-mediated formation of alternative lengthening of telomeresassociated PML bodies requires HIRA but not ASF1a. PLoS One, 6: e17036.

Jorcano, J.L. and Ruiz-Carrillo, A. 1979. H3.H4 tetramer directs DNA and core histone octamer assembly in the nucleosome core particle. Biochemistry, 18: 768-774.

Kaufman, P.D., Kobayashi, R., Kessler, N., and Stillman, B. 1995. The p150 and p60 subunits of chromatin assemblyfactor I: A molecular link between newly synthesized histories and DNA replication. Cell, $\mathbf{8 1}$ :
$1105-1114$

Kirov, N., Shtilbans, A., and Rushlow, C. 1998. Isolation and characterization of a new gene encoding a member of the HIRA family of proteins from Drosophila melanogaster. Gene, 212: 323-332.

Kleinschmidt, J.A., Dingwall, C., Maier, G., and Franke, W.W. 1986. Molecular characterization of a karyophilic, histone-binding protein: cDNA cloning, amino acid sequence and expression of nuclear protein $\mathrm{N} 1 / \mathrm{N} 2$ of Xenopus laevis. EMBO J., 5: 3547-3552.

Kose, S., Imamoto, N., Tachibana, T., Shimamoto, T., and Yoneda, Y. 1997. Ran-unassisted nuclear migration of a $97-\mathrm{kD}$ component of nuclear pore-targeting complex. J. Cell Biol., 139: 841-849.

Lamour, V., Lecluse, Y., Desmaze, C., Spector, M., Bodescot, M., Aurias, A., Osley, M.A., and Lipinski, M. 1995. A human homolog of the S.cerevisiae HIR1 and HIR2 transcriptional repressors cloned from the DiGeorge syndrome critical region. Hum. Mol. Genet., 4: 791-799.

Laskey, R.A., Honda, B.M., Mills, A.D., and Finch, J.T. 1978. Nucleosomes are assembled by an acidic protein which binds histones and transfers them to DNA. Nature, 275: 416-420.

Lemaire, P., Garrett, N., and Gurdon, J. 1995. Expression cloning of Siamois, a xenopus homeobox gene expressed in dorsal-vegetal cells of blastulae and able to induce a complete secondary axis. Cell, 81: 85-94.

Lohka, M.J. and Masui, Y. 1983. Formation in vitro of sperm pronuclei and mitotic chromosomes induced by amphibian ooplasmic components. Science, 220: 719-721.

Loppin, B., Bonnefoy, E., Anselme, C., Laurençon, A., Karr, T.L., and Couble, P. 2005. The histone H3.3 chaperone HIRA is essential for chromatin assembly in the male pronucleus. Nature, 437: 1386-1390.

Mello, J.A., Silljé, H.H.W., Roche, D.M.J., Kirschner, D.B., Nigg, E.A., and Almouzni, G. 2002. Human Asf1 and CAF-1 interact and synergize in a repair-coupled nucleosome assembly pathway. EMBO Rep., $\mathbf{3}$ : 329-334

Moggs, J.G., Grandi, P., Quivy, J.P., Jónsson, Z.O., Hübscher, U., Becker, P.B., and Almouzni, G. 2000. A CAF-1-PCNA-mediated chromatin assembly pathway triggered by sensing DNA damage. Mol. Cell. Biol., 20: $1206-1218$.

Murray, A.W. 1991. Cell cycle extracts. Methods Cell Biol., 36: 581-605.

Murzina, N.V., Pei, X.Y., Zhang, W., Sparkes, M., Vicente-Garcia, J., Pratap, J.V., McLaughlin, S.H., Ben-Shahar, T.R., Verreault, A., Luisi, B.F., and Laue, E.D. 2008. Structural basis for the recognition of histone $\mathrm{H} 4$ by the histone-chaperone RbAp46. Structure, 16: 1077-1085.

Nashun, B., Hill, P.W.S., Smallwood, S.A., Dharmalingam, G., Amouroux, R., Clark, S.J., Sharma, V., Ndjetehe, E., Pelczar, P., Festenstein, R.J., Kelsey, G., and Hajkova, P. 2015. Continuous Histone Replacement by Hira Is Essential for Normal Transcriptional Regulation and De Novo DNA Methylation during Mouse Oogenesis. Mol. Cell, 60: 611-625.

Natsume, R., Eitoku, M., Akai, Y., Sano, N., Horikoshi, M., and Senda, T. 2007. Structure and function of the histone chaperone CIA/ASF1 complexed with histones H3 and H4. Nature, 446: 338-341.

Ohsumi, K., Yamamoto, T.M., and Iwabuchi, M. 2006. Oocyte extracts for the study of meiotic M-M transition. Methods Mol. Biol., 322: 445458.

Philpott, A., Krude, T., and Laskey, R.A. 2000. Nuclear chaperones. Semin. Cell Dev. Biol., 11: 7-14.

Rai, T.S., Puri, A., McBryan, T., Hoffman, J., Tang, Y., Pchelintsev, N.A., van Tuyn, J., Marmorstein, R., Schultz, D.C., and Adams, P.D. 2011. Human CABIN1 is a functional member of the human HIRA/UBN1/ ASF1a histone H3.3 chaperone complex. Mol. Cell. Biol., 31: 41074118.

Ray-Gallet, D., Quivy, J.P., Scamps, C., Martini, E.M.D., Lipinski, M., and Almouzni, G. 2002. HIRA is critical for a nucleosome assembly pathway independent of DNA synthesis. Mol. Cell, 9: 1091-1100.

Ray-Gallet, D. and Almouzni, G. 2004. DNA synthesis-dependent and 
-independent chromatin assembly pathways in Xenopus egg extracts. Methods Enzymol., 375: 117-131.

Ray-Gallet, D., Quivy, J.P., Silljé, H.W.W., Nigg, E.A., and Almouzni, G. 2007. The histone chaperone Asf1 is dispensable for direct de novo histone deposition in Xenopus egg extracts. Chromosoma, 116: 487-496.

Ray-Gallet, D., Woolfe, A., Vassias, I., Pellentz, C., Lacoste, N., Puri, A., Schultz, D.C., Pchelintsev, N.A., Adams, P.D., Jansen, L.E.T., and Almouzni, G. 2011. Dynamics of histone H3 deposition in vivo reveal a nucleosome gap-filling mechanism for H3.3 to maintain chromatin integrity. Mol. Cell, 44: 928-941.

Ruthenburg, A.J., Wang, W., Graybosch, D.M., Li, H., Allis, C.D., Patel, D.J., and Verdine, G.L. 2006. Histone $\mathrm{H} 3$ recognition and presentation by the WDR 5 module of the MLL1 complex. Nat. Struct. Mol. Biol., 13: 704-712.

Sawada, K., Fukushima, Y., and Nishida, H. 2005. Macho-1 functions as transcriptional activator for muscle formation in embryos of the ascidian Halocynthia roretzi. Gene Expr. Patterns, 5: 429-437.

Schneiderman, J.I., Orsi, G.A., Hughes, K.T., Loppin, B., and Ahmad, K. 2012. Nucleosome-depleted chromatin gaps recruit assembly factors for the H3.3 histone variant. Proc. Natl. Acad. Sci. USA, 109: 1972119726.

Sharp, J.A., Franco, A.A., Osley, M.A., and Kaufman, P.D. 2002. Chromatin assembly factor I and Hir proteins contribute to building functional kinetochores in S. cerevisiae. Genes Dev., 16: 85-100.

Sherwood, P.W., Tsang, S.V., and Osley, M.A. 1993. Characterization of HIR1 and HIR2, two genes required for regulation of histone gene transcription in Saccharomyces cerevisiae. Mol. Cell. Biol., 13: 28-38.

Shibahara, K. and Stillman, B. 1999. Replication-dependent marking of DNA by PCNA facilitates CAF-1-coupled inheritance of chromatin. Cell, 96: 575-585.

Shintomi, K., Iwabuchi, M., Saeki, H., Ura, K., Kishimoto, T., and Ohsumi, K. 2005. Nucleosome assembly protein-1 is a linker histone chaperone in Xenopus eggs. Proc. Natl. Acad. Sci. USA, 102: 82108215.

Song, J.J., Garlick, J.D., and Kingston, R.E. 2008. Structural basis of his- tone H4 recognition by p55. Genes Dev., 22: 1313-1318.

Tachiwana, H., Osakabe, A., Shiga, T., Miya, Y., Kimura, H., Kagawa, W., and Kurumizaka, H. 2011. Structures of human nucleosomes containing major histone $\mathrm{H} 3$ variants. Acta Crystallogr. Sect. D Biol. Crystallogr, 67: 578-583.

Tagami, H., Ray-Gallet, D., Almouzni, G., and Nakatani, Y. 2004. Histone H3.1 and H3.3 complexes mediate nucleosome assembly pathways dependent or independent of DNA synthesis. Cell, 116: 51-61.

Tang, Y., Poustovoitov, M.V., Zhao, K., Garfinkel, M., Canutescu, A., Dunbrack, R., Adams, P.D., and Marmorstein, R. 2006. Structure of a human ASF1a-HIRA complex and insights into specificity of histone chaperone complex assembly. Nat. Struct. Mol. Biol., 13: 921-929.

Tyler, J.K., Adams, C.R., Chen, S.R., Kobayashi, R., Kamakaka, R.T., and Kadonaga, J.T. 1999. The RCAF complex mediates chromatin assembly during DNA replication and repair. Nature, 402: 555-560.

Verreault, A., Kaufman, P.D., Kobayashi, R., and Stillman, B. 1996. Nucleosome assembly by a complex of CAF-1 and acetylated histones H3/H4. Cell, 87: 95-104.

Xu, C. and Min, J. 2011. Structure and function of WD40 domain proteins. Protein Cell, 2: 202-214.

Yamamoto, T.M., Iwabuchi, M., Ohsumi, K., and Kishimoto, T. 2005. $\mathrm{APC} / \mathrm{C}-\mathrm{Cdc} 20$-mediated degradation of cyclin B participates in CSF arrest in unfertilized Xenopus eggs. Dev. Biol., 279: 345-355.

Zhang, R., Poustovoitov, M.V., Ye, X., Santos, H.A., Chen, W., Daganzo, S.M., Erzberger, J.P., Serebriiskii, I.G., Canutescu, A.A., Dunbrack, R.L., Pehrson, J.R., Berger, J.M., Kaufman, P.D., and Adams, P.D. 2005. Formation of macroH2A-containing senescence-associated heterochromatin foci and senescence driven by ASF1a and HIRA. Dev. Cell, 8: $19-30$.

Zhang, R., Chen, W., and Adams, P.D. 2007. Molecular dissection of formation of senescence-associated heterochromatin foci. Mol. Cell. Biol., 27: 2343-2358.

(Received for publication, January 24, 2017, accepted, February 8, 2017 and published online, April 4, 2017) 